\title{
Recuerdo del arabista tangerino Ricardo Ruíz Orsatti en el centenario de la muerte de Galdós
}

\section{Memory of the tangerine arabist Ricardo Ruíz Orsatti on the centenary of Galdós'death}

\section{Bernabé LÓPEZ GARCÍA}

Universidad Autónoma de Madrid ${ }^{1}$

bernabe.lopezg@uam.es

https://orcid.org/0000-0001-6418-6228

Para citar este artículo: Bernabé LÓPEZ GARCÍA (2020): "Recuerdo del arabista tangerino Ricardo Ruíz Orsatti en el centenario de la muerte de Galdós" em Revista de Estudios Internacionales Mediterráneos, 28, pp. 180-202.

Para acceder a este artículo: https://doi.org/10.15366/reim2020.28.010

\section{Resumen}

Se suele confundir la historia del arabismo español con la del gremio universitario pero debe tenerse en cuenta también el papel desempeñado por los traductores e intérpretes del árabe, en el que debe recordarse a los hermanos Ruíz Orsatti, Ricardo y Reginaldo. Ricardo Ruíz Orsattidesempeñó un papel importante en las relaciones hispano-marroquíes en la primera mitad del siglo XX. Pero su nombre es especialmente conocido por la correspondencia que mantuvo con el escritor Benito Pérez Galdós entre 1901 y 1910, que sería decisiva para la redacción por el novelista de dos de sus episodios nacionales, Aita Tettauen y Carlos VI en la Rápita. El centenario de la muerte del escritor canario parece una ocasión propicia para situar esta correspondencia en su contexto y rescatar la figura de Ricardo Ruíz Orsatti.

Palabras Clave:Arabismo/Ruíz Orsatti/ Galdós/ Guerra de Tetuán/ Tánger

\section{Abstract}

The history of Spanish Arabism is often confused with that of the academic discipline, but the role played by Arabic translators and interpreters must also be taken into account, in which the brothers RuízOrsatti, Ricardo and Reginaldo must be remembered.Ricardo RuízOrsatti played an important role in Spanish-Moroccan relations in the first half of the 20th century. But his name is especially known for the correspondence he had with the writer Benito Pérez Galdós between

${ }^{1}$ Catedrático honorario de Estudios Árabe e Islámicos, Universidad Autónoma de Madrid. Codirector del Taller de Estudios Internacionales Mediterráneos 
1901 and 1910, which would be decisive for the drafting by the novelist of two of his national episodes.AitaTettauen y Carlos VI en la Rápita. The centenary of the death of the Canarian writer seems a propitious occasion to place this correspondence in its context and rescue the figure of Ricardo RuízOrsatti.

Keywords: Arabism/RuízOrsatti/ Galdós/ Hispano-Moroccan War (1859-1860)/ Tánger

Se suele confundir la historia del arabismo español con la del gremio universitario pero debe tenerse en cuenta también el papel desempeñado por los traductores e intérpretes del árabe, en el que debe recordarse a los hermanos Ruíz Orsatti, Ricardo y Reginaldo, nacidos en Tánger respectivamente en 1871 y 1873. Hijos de Francisco Ruíz y Gordillo, comerciante nacido en Corumbela (Málaga) en 1831 y llegado a Tánger en 1850, donde casó, en segundas nupcias, con la tangerina Luisa Orsati ${ }^{2}$, forman parte de una saga que tuvo su continuidad en el diplomático e historiador Teodoro Ruíz de Cuevas, que desempeñaría un papel relevante en las relaciones hispano-árabes entre las décadas de 1940-1970.

La labor de Reginaldo, funcionario de la administración española, en la que ejerció tareas de intérprete para el ministerio de Estado, es más conocida por su papel en la intermediación con el Raisuni y por su mayor contacto con el arabismo académico a través de su papel en la revista $A l$ Andalus, en la que dirigió la sección de "Estudios marroquíes y dialectología"3 y fue miembro de su comité de redacción desde su creación en 1932 hasta su muerte en $1945^{4}$.

Menos conocida es la labor de su hermano, Ricardo. Se sabe poco de su formación, en la que, como se señala en un documentado apunte biográfico, "no llegó a cursar formación media y superior" ${ }^{\prime 2}$. En los años escolares del arabista, la enseñanza en la ciudad de Tánger para los niños españoles estuvo en manos de la Misión Católico-Española, regida por la orden franciscana, a impulsos del Padre Lerchundi, con ayuda de la Legación española. Hasta 1886 no se abrieron en Tánger cursos de segunda enseñanza en el Colegio de San Buenaventura, en la barriada de San Francisco, vinculados al Instituto de Cádiz ${ }^{6}$. No sabemos si Ricardo pudo tener acceso a esta institución. Lo que parece evidente por su trayectoria profesional fue que adquirió un buen dominio del árabe ya que, según la nota biográfica citada, se le destinó en 1891 a la cancillería del Consulado español de Tetuán7 y, entre 1898 y 1917, ocupó el cargo de vicecónsul e intérprete de la Legación rusa en Tánger. Fue director de la Escuela Hispano-Árabe de Tánger, creada en 1907 y en 1916, iniciado ya el Protectorado de España, fue nombrado inspector general de la enseñanza hispano-árabe en Marruecos. Dos años antes había colaborado con Julián Ribera durante el viaje

\footnotetext{
${ }^{2}$ Los datos de los padres están sacados del Libro de matrícula de españoles residentes en la ciudad de Tánger, año de 1867, en el Archivo del Consulado General de Tánger. El apellido de la madre aparece escrito con una sola " $\mathrm{t}$ ".

${ }^{3}$ Ver Marín, Manuela: "Orientalismo en España: estudios árabes y acción colonial en Marruecos (1894-1943)", en Hispania, 2009, vol. LXIX,núm. 231, enero-abril, pág. 132. En el volumen 2, no 1 de 1934 de la revista Al Andalus, Ricardo Ruíz Orsatti publicó el artículo "Guerra de África de 1859-1860, según un marroquí de la época".

${ }^{4}$ Mourad Zarrouk se refiere en extenso a la labor de Reginaldo en su libro Los traductores de España en Marruecos (1858-1939), Colección Alborán, Ed. Bellaterra, Barcelona 2009.

5Irene González González: "Ricardo Ruíz Orsatti" en La historia trascendida: http://www.lahistoriatrascendida.es/documentos/personajeshistoricos/RuizOrsatti.pdf

${ }^{6}$ Ver Antonio P. Félix, Labor de las Escuelas Hispano-Franciscanas en Tánger, Tánger 1930, p. 4.

${ }^{7}$ Fruto de esa circunstancia acabaría casándose con la hija del cónsul Teodoro de Cuevas, Julia, matrimonio del que nacería el citado Teodoro Ruíz de Cuevas.
} 
que este realizó al norte del país para la elaboración de una "Memoria sobre la situación presente de la enseñanza en el Protectorado de España en Marruecos". En 1918 Ricardo publicaría en Tetuán un extenso informe sobre La enseñanza en Marruecos $^{8}$.

Cuando se puso en vigor el Estatuto internacional de Tánger, Ricardo Ruíz Orsatti fue nombrado por el gobierno español en octubre de 1924 administrador adjunto, con competencia en los servicios de Higiene y Beneficencia ${ }^{9}$. En paralelo, y entre octubre de 1924 y febrero de 1926, dirigió los Servicios Especiales Reservados, un servicio de espionaje que tomó el relevo de la Oficina de Información de Tánger creada en 1916 por el Alto Comisario Gómez Jordana y el jefe de la Legación española en la ciudad, Francisco Serrat y Bonastre ${ }^{10}$.

Ricardo Ruíz Orsatti desempeñó un papel importante en las relaciones hispano-marroquíes en la primera mitad del siglo XX. En 1944 publicó un libro misceláneo titulado Relaciones hispanomarroquíes $^{11}$. A lo largo de muchos años fue realizando una labor de recopilación de recortes de periódicos sobre estas relaciones que, encuadernados, se conservan en la Biblioteca de Tetuán, antigua Biblioteca General del Protectorado, en la colección denominada Miscelánea Ruíz Orsatti.

Pero su nombre se asocia especialmente al de Benito Pérez Galdós por la correspondencia que mantendrá con el escritor entre 1901 y 1910, que sería decisiva para la redacción por el novelista de dos de sus episodios nacionales, Aita Tettauen y Carlos VI en la Rápita. El centenario de la muerte del escritor canario parece una ocasión propicia para situar esta correspondencia en su contexto y rescatar la figura de Ricardo Ruíz Orsatti.

Esta correspondencia fue conocida gracias a un artículo titulado "Aita Tettauen" que el intérprete publicó en un número extraordinario del periódico La Gaceta de África "dedicado a la obra de España en Marruecos", aparecido en enero de 1935, que dio pie a que el hispanista francés Robert Ricard divulgase la "génesis" del episodio galdosiano ${ }^{12}$ y, años más tarde en 1968, publicase las cartas del intérprete a Galdós ${ }^{13}$, hoy consultables on line en la Biblioteca Virtual Miguel de Cervantes ${ }^{14}$ y que se reproducen aquí.

Según Ruíz Orsatti en el artículo citado y como puede verse también en la propia correspondencia, enterado en febrero de 1901 por la prensa de la intención del novelista de escribir "un relato de la Guerra de Tetuán desde el punto de vista marroquí", le escribió ofreciéndole la traducción de un capítulo de la obra del historiador marroquí Sid Ahmed Ben Jáled En-Nasiri, el Kitab al Istiqsàtarijal

\footnotetext{
${ }^{8}$ Ver las páginas que dedica a este libro Irene González González (2015): Escuela e ideología en el Protectorado español en el norte de Marruecos (1912-1956), Ediciones Bellaterra-Casa Árabe, pp. 95-100.

${ }^{9}$ En La Vanguardia de 29 de octubre de 1924 aparece noticia de su nombramiento, considerado como un acierto. Se le califica de "persona muy competente y de sólida preparación, que cuenta con gran prestigio y simpatías, no sólo entre la colonia española sino también entre los restantes elementos de esta población". En el desempeño de este cargo publicó losinformesMemoria anual de los Servicios de Higiene y Beneficencia del año 1926; Memoria quinquenal 19271931; Memoria sobre la plaga de la langosta en 1929 y La peste en Tánger en 1934. Una entrevista sobre su gestión se encuentra en el primer número de la revista Tanger-Riviera aparecido en septiembre de 1937, que puede encontrarse on line.

${ }^{10}$ Sobre esta función ejercida por Ruíz Orsatti véase el artículo de Julián Paniagua López, "La red de servicios secretos españoles durante la guerra del Rif (1921-1927): los Servicios Especiales Reservados dirigidos por Ricardo Ruíz Orsatti", en Historia Contemporánea, 57, 2018: 491-521.

${ }^{11}$ Publicaciones África, Madrid 1944.

12 Ricard, Robert : "Note sur la genèse de I'"AitaTettauen" de Galdós », en Bulletin Hispanique, tome 37, n4, 1935. pp. 473-477.

${ }^{13}$ Ricard, Robert: “Cartas de Ricardo Ruiz Orsatti a Galdós acerca de Marruecos (1901-1910)", en Anales Galdosianos, Cabildo Insular de Gran Canaria, Año III, 1968.

${ }^{14}$ http://www.cervantesvirtual.com/obra-visor/anales-galdosianos--23/html/0254c9a6-82b2-11df-acc7$\underline{002185 \text { ce6064 70.html\#1 } 36}$
} 
Magrib en el que se narraba dicha guerra desde la óptica marroquí. Esta obra había aparecido publicada elEl Cairo en cuatro volúmenes en 1894 y Ruíz Orsatti tuvo acceso a un ejemplar.

La obra, una historia de Marruecos, contaba con un capítulo dedicado a los Alauíes en el que se trataba de la guerra de Tetuán de 1859. Según cuenta Ricard, intrigaba, antes de que Ruíz Orsatti diera a conocer este hecho, cómo Galdós hubiera podido tener acceso a la obra del historiador marroquí que no fue traducida, y al francés, hasta 1906-7 en los Archives Marocaines. El novelista convierte a uno de sus personajes, El-Nasiry, en narrador de la guerra desde una óptica marroquí en la tercera parte de la obra.

No respondió de inmediato Galdós, inmerso en la polémica que el estreno de su obra Electra produjo en España ${ }^{15}$, al ofrecimiento de Ruíz Orsatti en febrero de 1901 del capítulo traducido, por lo que unos meses más tarde insistió con una nueva carta, de la que sí obtuvo respuesta. El novelista acogió favorablemente el ofrecimiento y sugerencia del intérprete, que firmaba su carta como "Drogmán de la Legación Imperial de Rusia". Precisamente la tercera de las cartas de Ruíz Orsatti está escrita a punto de viajar a una misión en San Petersburgo, y en ella empieza a contestar a algunas de las cuestiones que el novelista comenzaba a plantearle: nombres musulmanes de personas, sugerencias sobre transcripción de términos árabes.

Transcurrido año y medio, parece por la carta de 18 de septiembre de 1902 que Galdós muestra su interés de viajar a Marruecos para conocer de cerca el terreno y escenario de su episodio, ya que Ruíz le dice haber encontrado una casa de hebreos donde poder instalarse durante su visita y "vivir en familia con más holgura y libertad y mejor atendido que en un hotel".

Sin embargo el viaje no se llevará a cabo hasta dos años más tarde, como muestra la propia cronología de la correspondencia. Galdós debió informarle de su decisión de viajar en su carta del 25 de septiembre, respondida cuatro días más tarde por el intérprete, que le ofrecía su casa para alojarse, su apoyo para trámites a su llegada e indicaciones para desplazarse a Tetuán, mejor por mar que por tierra:

"Así es que para ir a Tetuán no sería prudente hacer el viaje por la vía terrestre, como en otros tiempos menos inquietos. Hay que ir por mar, y seguramente en los días que $\mathrm{V}$. permanezca aquí no faltará ocasión de realizar el viaje en alguno de los vapores que con frecuencia hacen esa escala".

El periódico tangerino en español, El Porvenir, dirigido por Francisco Ruíz López, dará la noticia el 11 de octubre de 1904 de la llegada de Galdós esa mañana a Tánger desde Algeciras, con la intención de "completar datos para un nuevo libro, consagrado a Prim y a la guerra de África"16.

Alojado en el Hotel Cecil, por entonces en la playa tangerina, permaneció nueve días, en los que sería agasajado por elementos de la colonia española. Del 13 de octubre data una de las notas que se conserva en la correspondencia, en la que Ruíz, que fue su anfitrión durante su estancia, le invita a asistir a la recepción por las autoridades moras del nuevo ministro de Austria a la que asistiría Mohamed Torres, personaje que ejercía la función de ministro de Exteriores del sultán ${ }^{17}$.

De la estancia en Tánger de Galdós se conserva una foto durante una "jira al campo" acompañado de "un grupo de intelectuales tangerinos" con sus familias, publicada años más tarde en el libro de

\footnotetext{
15 Véase en La Correspondencia de España de febrero de 1901 la expectación y críticas que levantó la obra en determinados sectores, con manifestaciones de apoyo o de boicot.

${ }^{16}$ Agradezco a Antonio Reyes que me localizó en la hemeroteca de la Biblioteca de Tetuán los ejemplares de El Porvenir y La Gaceta de África citados en este artículo.

${ }^{17}$ Torres (1820-1908) fue el representante del sultán de Marruecos en la Conferencia de Algeciras en 1906.
} 
Isaac Laredo Memorias de un viejo tangerino ${ }^{18}$. En la carta de Ruíz a Galdós fechada el 15 de enero de 1905, aquél le recuerda que "Abensur y otros amigos desean hacer unas ampliaciones del adjunto grupo y me encargan suplique a $\mathrm{V}$. tenga la bondad de pedir a Victoriano que nos mande la placa". Esta debió ser remitida a Tánger, pues Ruíz le informa que el hijo de Cólogan, el ministro de España en Tánger $^{19}$, la había recibido. Es probable que entre los que acompañan a Galdós en la foto estuvieran Abensur, representante de la banca Pariente en Tánger, Cólogan, Ruíz y el propio Laredo, lo que explicaría la reproducción en su libro.

Victoriano, según el historiador de la fotografía y académico de Bellas Artes Publio López Mondéjar, era Victoriano Moreno, el fotógrafo amateur amigo de Galdós que acompañó al escritor en su viaje tangerino, y de él son también tres fotografías en las que aparece en el palacio del gobernador de Tánger Sidi Ben Hima, a caballo junto al sargento Hamet de la Legación de España y junto a un moro y unos españoles en una aldea tangerina. Las fotos fueron publicadas en una entrevista que le hizo Manuel Carretero, aparecida en la revista Por esos mundos en 1905 ( $\mathrm{n}$ 123-IV), poco después de que saliese a la calle el episodio de Aita Tettauen.

En este viaje a Tánger tuvo la oportunidad Galdós de conocer en persona a quien habría de ser uno de los personajes de su episodio, Aníbal Rinaldy, intérprete que fue del general O’Donnell durante la guerra de Tetuán, y que por entonces vivía ya retirado en Tánger y afectado de una enfermedad de la vista que le impedía escribir. En la carta de 28 de abril de 1905 Ruíz transmite a Galdós el agradecimiento del propio Rinaldy al autor por "el retrato que de él hace" en la novela. Galdós lo idealiza y lo convierte en un "simpático mozo", "más bien niño", cuando el personaje real contaba ya con 36 años en el momento de la guerra. Tal vez se prestara a esa confusión la denominación que se daba a los intérpretes como "jóvenes de lenguas".

En víspera de su partida, el 18 de octubre se celebró en el Hotel Bristol un "banquete íntimo" con el novelista organizado por un "buen número de españoles admiradores del eximio escritor", según El Porvenir. Y al día siguiente el periódico daba cuenta de que en el vapor Piélago había partido Galdós hacia "Algeciras, de donde seguirá viaje a Ceuta", despedido por una nutrida concurrencia de compatriotas ${ }^{20}$.

Pero las inclemencias del tiempo le impidieron embarcarse desde Algeciras para Ceuta a fin de llevar a cabo su viaje a Tetuán. Así lo narrará en carta desde Algeciras a Ruíz Orsatti: "Yo he renunciado a pasar nuevamente el Estrecho si el maldito Eolo no calma su furia" ${ }^{21}$. Finalmente optó por retornar a Madrid, vía Granada, contentándose "con las impresiones puramente imaginativas que he podido recibir de Ud. y otros amigos y que ahora reforzaré con los testigos vivientes de la campaña que por aquí andan todavía"22.

El 27 de octubre Ruíz responde aprobando las justificaciones de Galdós para no atreverse a realizar el viaje a Tetuán y aprovecha para hacerle indicaciones sobre toponimias morunas. Por entonces Galdós se encierra, entre octubre de 1904 y enero de 1905, para la redacción del episodio nacional de Aita Tettauen. No parece haber respondido a Ruíz hasta el 19 de diciembre en que le escribe una larga carta de la que el intérprete reproduce largos extractos en su artículo de $1935^{23}$. En ella le explica el plan de la obra, las cuatro partes en que había dividido la narración,

\footnotetext{
18 Tánger, 1935.

${ }^{19}$ Bernardo Cólogan y Cólogan (1847-1921), marqués de la Candia, dirigió la Legación española en Tánger entre 1902 y 1905.

${ }^{20}$ El periódico El Liberal publicaría los días 12 y 20 de octubre de 1904 la noticia de su llegada y la de la del homenaje de despedida.

${ }^{21}$ Ruíz Orsatti en La Gaceta de África.

${ }^{22}$ Ibid.

${ }^{23}$ Extractos que pueden leerse en la transcripción de las cartas que se publica en este mismo artículo.
} 
con las dos perspectivas, española y marroquí, bajo las que había querido escribir la historia. A esta carta Ruíz respondió, según dice en su artículo de La Gaceta de África, "con el apresuramiento que nuestra admiración al glorioso maestro nos imponía". Pero en la correspondencia conservada no parece que el apresuramiento fuera grande, pues la siguiente carta es del 15 de enero, cuando la obra estaba ya terminada y las extensas explicaciones que Ruíz aportaba sobre el nombre del protagonista marroquí dado por Galdós, Sidi Mohammed Hach Ben Sur el Nasiry, sobre la denominación de los meses musulmanes, de las puertas y el callejero de Tetuán, "llegaban tarde".

El 11 de febrero Galdós se lamenta de no haber recibido a tiempo la carta de Ruíz, justificándose por los errores que quedaron en la obra.

La correspondencia no concluye con el intercambio de noticias para la redacción de Aita Tettauen. Ruíz responde el 17 y el 23 de febrero anunciándole que no resistió la tentación de esperar el ejemplar del episodio que el autor le mandaba y compró uno que leyó de un tirón. Con su natural zalamero continúa, en una extensa carta, aportando datos geográficos y de toponimia sobre la zona, así como expresiones del habla árabe y judía de Tetuán, con vistas al siguiente episodio, Carlos VI en la Rápita, que el escritor había comenzado.

Tras la carta del 28 de abril de 1905, la correspondencia no se reanuda hasta el 14 de agosto de 1908 en que Ruíz anuncia a Galdós que iba a publicar una Revista Española y de Intereses Generales, de periodicidad quincenal, para cuyo primer número le solicita unas cuartillas sobre su viaje a Marruecos. Probablemente Galdós no respondió al requerimiento de Ruíz Orsatti, ya que no hay otra carta hasta la del 25 de octubre de 1910, a la vuelta del intérprete y profesor de una excursión por el Rif para la elaboración de un libro que iba a titular "Desde el Muluya al Sebú", para el que redactaría unos trabajos sobre la cabilas de Anyera, Uadras y Fahs, limítrofes a Tánger ${ }^{24}$. En esta última carta solicita de Galdós recomendación para optar a dirigir un "Centro de Estudios Marroquíes" que, según dice, iba a ser proyectado por el Ministerio de Estado y del que decía que "su falta se hacía sentir para acabar con tanta fantasía morisca como ha propagado la nutrida literatura hispano-marroquí". Ruíz le decía, "sin huera vanidad", estar "en condiciones, que ningún otro español puede reunir, para dirigir ese centro, y para conseguir este propósito es para lo que hoy me decido a molestarle, rogándole me perdone la molestia que le ocasiono" 25 .

Del carácter de Ricardo Ruíz Orsatti traza un perfil no muy halagüeño Francisco Serrat y Bonastre, ministro de España que fue en Tánger entre 1916 y 1925 en sus memorias ${ }^{26}$ :

"Como su hermano Reginaldo, era perito en el conocimiento del árabe. Más base de cultura no se la he conocido. Sin embargo, por su prosopopeya y su marrullería lograba

\footnotetext{
24 “La kabila de El-Fahs", en el Boletín de la Real Sociedad Geográfica (BRSG), XLIX (primer trimestre 1907), pp. 84-109; "La kabila de Anyra", en BRSG, L (primer trimestre 1908), pp. 7-67. Contiene entre las páginas 58-61 un detallado estudio sobre el islote Perejil (Taura). "La kabila de Uadrás", en el Boletín Oficial de la Zona de influencia española en Marruecos, 10 y 25 de mayo de 1913, pp. 212-268 y 287-319. Este último estudio aparece realizado por Real Orden del Ministerio de Estado, 80 de 27 de marzo de 1911. El libro "Desde el Muluya al Sebú" nunca se publicó.

${ }^{25}$ La pretensión de Ruíz Orsatti era que Galdós lo recomendase directamente o publicase en la prensa un artículo en recuerdo de Aita Tettauen encomiando las aptitudes del intérprete. El Centro de Estudios Marroquíes aparecía citado en la Gaceta de Madrid de 3 de julio de 1910, p. 184, en el Proyecto de Ley de presupuestos generales del Estado, en el apartado del Ministerio de Estado, Gastos diversos, bajo la rúbrica "Para subvención a un Instituto libre de enseñanza de las materias que constituyen las carreras Diplomática y Consular para organización del un Centro de Estudios Marroquíes", con una asignación de 50.000 pesetas. Manuela Marín hace referencia en el artículo citado, p. 127, al Centro, que se creó, con no demasiada fortuna, vinculado a la Real Academia de Jurisprudencia y Legislación por Real decreto (Gaceta de 29 de diciembre de 1911).

${ }^{26}$ Tánger 1916-1924 (Radiografía de la ciudad del Estrecho en vísperas del Estatuto), Editorial Almed, Granada 2017. Introducción y edición a cargo de B. López García, p. 180.
} 
inspirar impresión de intelectual y a fuerza de aparentarlo sin duda había adquirido algunos conocimientos útiles que le daban cierto crédito en nuestros centros gubernamentales. Por esta razón, sobre regir la escuela indígena (que no daba grandes frutos) era un elemento casi indispensable en la Comisión de Higiene. Hacía frecuentes viajes a Madrid y a Tetuán para arrimarse al mando, cerca del cual gozaba de mayor crédito del que se merecía. De este modo logró nada menos que el cargo de Administrador adjunto al implantarse el Estatuto. Su influencia en la colonia era relativa. Inspiraba más temor que respeto. No era elemento perturbador, pero había que cuidarlo".

II

\section{Correspondencia entre Ricardo Ruíz Orsatti y Benito Pérez Galdós.}

(Se sigue la transcripción más arriba indicada de la Biblioteca Virtual Miguel de Cervantes y se incluyen fragmentos de las cartas de Galdós a Ruíz Orsatti transcritas del artículo de éste en el número extraordinario de La Gaceta de África de 1935.)

Tánger, 17 de Febrero de 1901.

Señor Don Benito Pérez Galdós,

Madrid.

Muy respetable Señor mío:

Enterado, por haberlo leído en "La Correspondencia de España», que tenía V. el propósito de publicar, como continuación a sus interesantísimos Episodios Nacionales, un relato de la Guerra de Tetuán desde el punto de vista marroquí, me permito ofrecer a V., como una muy pequeña prueba de admiración, la traducción hecha sin ninguna pretensión literaria, que va adjunta, de un capítulo de la Historia de Marruecos del Nasiry que a tal asunto se refiere y en el que tal vez halle V. algún dato utilizable.

En la misma obra dedica el autor otro capítulo al famoso Rugui, curiosa coincidencia ocurrida en aquella época de un pretendiente al trono xerifiano que se levantaba en armas contra su natural señor el Sultán Sidi Mohammed, al propio tiempo que en España se sofocaba en San Carlos de la Rápita la intentona carlista que trataba de destronar a doña Isabel Segunda.

Si cree V. que puede convenirle para su propósito, tendré una verdadera satisfacción en ponerlo a su disposición.

Ruego a V. dispense la libertad que me tomo y crea en la devoción que le profesa su admirador y seguro servidor,

Q. I. b. I. m.

Ricardo Ruiz

(rúbrica)

Drogmán de la Legación Imperial de Rusia 
Tánger, 4 junio de 1901.

Señor Don Benito Pérez Galdós.

Madrid.

Muy respetable señor mío:

Hace ya tiempo tuve el honor de enviar a V. la traducción de un capítulo de la Historia de Marruecos del Xej Ahmed El NasirySelaui referente a la Guerra de Tetuán del año 1859, por si pudiera servir a V. de alguna utilidad, y como no he tenido la satisfacción de que me acusara el recibo del mismo, en la duda de si lo habrá $V$. o no recibido, aunque iba en paquete certificado, me permito molestarle suplicando a $\mathrm{V}$. tenga a bien decírmelo, para en caso necesario hacer la reclamación a correos.

Aprovecho esta ocasión que me proporciona el honor de repetirme a V. muy atto. y devoto admirador y s. s.

Ricardo Ruiz

(rúbrica)

Tánger, 7 de Julio de 1901.

Señor Don B. Pérez Galdós.

Santander.

Muy respetable Señor y distinguido amigo: Acabo de ser favorecido con su muy atenta del 3 y me apresuro a contestar a V., porque, debiendo salir mañana para San Petersburgo llamado por el Gobierno Imperial, no quiero dejar de escribir a V., aunque sea a vuela pluma, para tener la satisfacción de dar a $\mathrm{V}$. los detalles que se sirve $\mathrm{V}$. pedirme.

En unos apuntes de una Escursión a Tetuán que publiqué en dos números de "Alrededor del Mundo", cuyos ejemplares tengo el honor de incluir, hallará V., si se toma la molestia de repasarlos, algunos apellidos de los principales moros oriundos de España y otros detalles referentes a los mismos. A esos apellidos se pueden agregar los de El Jetib, El Lebbady, El Delleso, El Zorby, El Ghalmia, también de distinguidas familias tetuaníes, granadinas de abolengo.

De varios modos dicen los moros Guerra de Tetuán. Aita Tettauen es el más y mejor usado; dicen también HarbTettauen, y también con frecuencia: «Aita maa el sbaniul»: guerra con el español.

A la guerra contra los infieles o sea la guerra santa llaman los árabes Yahad y a los guerreros que toman parte en ella Muyahidin (pronúnciase la $Y$ en ambas palabras como la $j$ francesa o catalana; la h se aspira suavemente, como en la palabra inglesa home [home]). A mi vuelta de Rusia tendré el gusto de escribir a V. más detenidamente sobre la pronunciación figurada de las palabras árabes de uso frecuente en español, que transcriben en España tanto en libros como en periódicos y documentos oficiales con la ortografía francesa o inglesa, diciendo, por ejemplo, Hadge (peregrino a la Meca) cuando debería escribirse, por ser más aproximado a la verdadera, Hach; o Anghera, en vez de escribir Anyera; Ouad o Wad, por Uad (río), etc. Me permito enviarle a V. un ejemplar de una obrita de mi hermano Reginaldo por si en ella puede $\mathrm{V}$. encontrar algo que pueda serle útil para su trabajo. 
Rogando a V. me mande siempre y como guste me repito de V. muy atto. s. s. y devoto admirador q. I. b. I. m.

Ricardo Ruiz

(rúbrica)

\section{4}

Una tarjeta postal con fotografías de Tolstoi y con la dirección siguiente: "Señor don Benito Pérez Galdós -Villa San Quintín- Santander (Espagne)». El texto dice así: «Desde la patria del gran ruso saluda al gran español su más devoto admirador que le besa la mano. -Ricardo Ruiz (rúbrica)». El matasellos del correo ruso lleva la fecha de San Petersburgo, 26 de julio de 1901.

\section{5}

(Texto escrito a máquina)

Tánger (Marruecos), 1 de julio de 1902.

Señor don Benito Pérez Galdós.

Madrid.

Muy respetable señor mío y de mi consideración más distinguida: En la cubierta de "LasTormentas del 48», primer tomo de la cuarta serie de sus monumentales Episodios Nacionales, he visto anunciado "Aita Tettauen». Otra vez en ésta de vuelta de mi viaje a Rusia, me apresuro a ofrecerme a $\mathrm{V}$. para todo aquello que $\mathrm{V}$. me crea útil, estando incondicionalmente a su disposición, para suministrarle todos los detalles que $V$. crea necesarios para la preparación de la historia de la guerra de Tetuán desde el punto de vista marroquí.

Con tal motivo le reitera a V. su admiración su más atento servidor y amigo que le besa la mano,

Ricardo Ruiz

\section{6}

Tánger, 18 de Septiembre 1902.

Señor Don Benito Pérez Galdós.

Santander.

Muy respetable Señor y amigo:

A su tiempo fui favorecido con su muy atenta del 18 julio, y, como me fue preciso ausentarme por aquellos días de Tánger, hasta mi vuelta no he podido ocuparme de cumplimentar el encargo conque me honra.

He encontrado lo que V. necesita y desea: Una casa de hebreos de la clase media donde podrá $\mathrm{V}$. vivir en familia con más holgura y libertad y mejor atendido que en un hotel. De precio nada he hablado, porque prefiero que se entienda V., llegado el momento, con sus hospederos en la seguridad de que quedará V. satisfecho. Únicamente ruego a V. me avise quince días, por lo menos, antes de su venida, para que en caso preciso pueda buscarle otro alojamiento si el que hoy 
he comprometido sin compromiso para V. no estuviera, por cualquier circunstancia, libre para entonces. Creo haber interpretado bien sus deseos. Vea V., pues, en que más puede serle útil, en la inteligencia de que en ello tendrá un verdadero placer su más atento amigo y admirador que le besa la mano

Ricardo Ruiz

(rúbrica)

Tánger, 29 Septiembre de 1904.

Señor Don Benito Pérez Galdós.

Madrid.

Mi muy respetable amigo: Con el mayor gusto me apresuro a contestar a su muy atenta del 25. ¿No me he de acordar de V., si soy uno de sus más convencidos admiradores?

En Tánger podrá V. permanecer todo el tiempo que a V. convenga. La tranquilidad aquí es completa. La paz (de los espíritus) no es turbada más que por unos cuantos cultivadores de "fantasías moriscas», que de vez en cuando alarman a la opinión por medio de la prensa, para justificar de alguna manera su fama de intrepidez temeraria, o para fines menos inocentes. Ya tendrá V. ocasión de conocer algunos tipos de esta especie, pues la especie abunda en ejemplares por aquí.

En todas las demás poblaciones del Imperio la tranquilidad es, como en Tánger, completa. En los caminos, es decir, en el campo, relativa. Así es que para ir a Tetuán no sería prudente hacer el viaje por la vía terrestre, como en otros tiempos menos inquietos. Hay que ir por mar, y seguramente en los días que $\mathrm{V}$. permanezca aquí no faltará ocasión de realizar el viaje en alguno de los vapores que con frecuencia hacen esa escala. En último caso y si, lo que no es probable, no hubiera en todo ese tiempo vapor directo, entonces habría que hacer el viaje a Ceuta desde aquí, para tomar en aquella plaza una barca, que en algunas horas (4 o 5) lo llevaría a Río Martín. De allí a Tetuán, 10 kilómetros que se recorren a caballo y en toda seguridad.

En cuanto a alojamiento, yo tendré un verdadero placer en que $\mathrm{V}$. tenga a bien aceptar en mi casa un modesto cuarto, y un plato, también modesto, pero limpio, en mi mesa. $Y$ esto tan sin cumplidos y a la pata la llana, que si a V. no conviniera, con idéntica llaneza me lo había de manifestar, para que juntos buscáramos mejor acomodo. A su criado no faltará donde alojarlo cerca de casa y en buenas condiciones. Para evitar molestias en esta Aduana al pasar el equipaje y otros inconvenientes, además del gusto que yo tengo en ir a esperar a V., le ruego me avise con anticipación el día fijo de su llegada a ésta. El vapor «Piélago» llega a ésta los lunes, miércoles y viernes de Cádiz, al mediodía, y los martes, jueves y sábados de Algeciras, a las 10, saliendo de ambos puertos para éste a las 7 de la mañana. Para que $V$. me conozca enseguida iré yo en el bote de la Sanidad.

Mande siempre con toda franqueza a su más atento amigo y admirador q.I.b.I.m.

Ricardo Ruiz

(rúbrica) 
Señor Don Benito Pérez Galdós.

Mi muy respetable amigo: Esta tarde a las 2 llega a ésta el nuevo Ministro de Austria y tendré que ir al muelle para saludarle. Si V. quiere presenciar la recepción que le hacen las autoridades moras a la cual asiste Torrés (es cosa de unos minutos), yo pasaré a recoger a V. al hotel un cuarto de hora antes, para desde allí ir después sin testigos inoportunos a ver al Gobernador, Abensur, etc.

Siempre de V. el más atento amigo y admirador,

Ricardo Ruiz

(rúbrica)

Jueves 13-X-904.

18-10-904

Tanger (Maroc)

Légation de Russie

Excmo. Señor

Don Francisco Fernández Bernal,

etc., etc., etc.,

Mi respetable Señor y amigo: La persona que le entregará esta tarjeta es don Benito Pérez Galdós. Su nombre ilustre es suficiente recomendación, por lo cual yo me limito a tener la honra de presentárselo a V., en la seguridad de que complacerá en cuanto pueda al futuro autor de Aita Tettauen. Julia me encarga cariñosos recuerdos a su Señora e hija (c. p. b.) y yo le suplico me crea su más atento servidor y respetuoso amigo q.I.b.I.m.

Ricardo Ruiz

(rúbrica)

Tanger (Maroc)

Légation de Russie

Mi querido Pepe:

El portador es Don Benito Pérez Galdós. Su nombre y representación hacen innecesarias toda clase de recomendaciones. Me limito, pues, a presentarte a mi respetable amigo en la seguridad de que harás cuanto puedas para que su estancia en ésa le sea grata y útil al fin que persigue su paso por esa plaza. Complacerás con ello muchísimo a tu pariente

Ricardo

(rúbrica)

Nuestros cariñosos recuerdos a Matilde.

Tánger, 18 Oct. 1904. 
Hotel Cecil

Tangier, Morocco

TelegraphicAddress

«Cecil, Tangier»

19 Octubre 1904

Señor Don Isaac Toledano.

Tetuán.

Mi querido amigo: El ilustre escritor español Don Benito Pérez Galdós tiene el proyecto de ir a pasar unos días en Tetuán con objeto de completar algunos datos para su futura producción Aita Tetauen (sic). Yo escuso recomendarte al portador porque su nombre es suficiente para un entusiasta como tú. Sirva pues ésta solamente como presentación, en la seguridad que yo tengo de que harás por mi respetable amigo cuanto puedas para que su estancia en ésa le sea grata y útil su paso por la santa ciudad de SidiSaidi.

Un abrazo de tu buen amigo

Ricardo Ruiz

(rúbrica)

Galdós a Ruíz Orsatti, Algeciras, 20 de octubre de 1904.

“(...) La travesía fue bastante desagradable. Llegué aquí con los ánimos bastante abatidos y al poner el pie en tierra me dijeron que el vapor de Ceuta no había venido. La noche ha sido ventosa, continuando el tiempo con la misma dureza de ayer. Resultó que el correo de Ceuta llegó anoche muy tarde. Ignoro si sale hoy. Yo he renunciado a pasar nuevamente el Estrecho si el maldito Eolo no calma su furia. Aquí me estoy pues esperando a mañana. Si mañana no está el tiempo en buena disposición, haré un viaje de penetración, marchándome a Granada y luego veremos. Yo tendré a Ud al tanto de lo que ordenen los designios de Allah (...)".

Galdós a Ruíz Orsatti, Madrid, 25 de octubre de 1904.

“(...) Se sorprenderá Ud de que le escriba tan pronto desde Madrid y más aún de saber que no fui al fin a Ceuta, sino a Granada y que de Granada me he recogido a esta metrópoli, donde permaneceré quieto y engolfado en mis trabajos durante un lapso de tiempo, que no puedo ahora precisar. En mi carta de Algeciras expresé a Ud mi desgana de volver a pasar el Estrecho, después de la travesía de Tánger a Algeciras, que fue tan penosa y desagradable. Pesadas en mi ánimo todas las contingencias probables y las ventajas y desventajas de una nueva excursión al África, decidí al fin volverme a mi casa. Realmente la perspectiva del viaje a Tetuán, como proponía el General B. ${ }^{27}$, en lancha, con poniente, no era muy seductora. Sobre que no habíamos de tener el poniente en el bolsillo para disponer de él a la ida, reservando en otro bolsillo el levante para la

27 (Nota de BLG) Se trata del general Francisco Fernández Bernal, al que el propio Ruíz escribió una nota recomendándole atendiera a Galdós durante su eventual paso por Ceuta. 
vuelta. Tal plan de viaje, por sus indudables molestias, tendría compensación en los encantos de la ciudad marroquí con sus gloriosas memorias. De no tener un vapor a mi disposición, valía más y era más práctico aplazar el viaje, contentándome hoy con las impresiones puramente imaginativas que he podido recibir de Ud y otros amigos y que ahora reforzaré con los testigos vivientes de la campaña que por aquí andan todavía (...)".

\section{2}

Tánger, 27 de Octubre de 1904.

Señor Don Benito Pérez Galdós.

Madrid.

Mi respetable amigo: Se me había ocurrido que renunciaría $V$. a su proyectada escursión a Ceuta y Tetuán, porque, si el tiempo era malo el día que V. se marchó, en los siguientes se desencadenó un furioso temporal y hubieran sido una temeridad atravesar el Estrecho. Después de todo y como $\mathrm{V}$. dice muy bien, no hubiera compensado las relativas bellezas de la ciudad santa de SidiSaidi a las positivas molestias que había V. de sufrir antes de llegar a ella.

Me he apresurado a cumplimentar su encargo; hoy mismo he escrito a mi cuñado para que devuelva a V. el pliego que habrá llegado a su poder esplicando al propio tiempo las circunstancias que a V. impidieron ir a Ceuta, con el ruego de que así lo haga saber al general señor Bernal.

Y vamos a lo que interesa. Es un error muy generalizado -tanto que yo también he incurrido en él en cierta ocasión por no fijarme el que comete Ros de Olano al afirmar que Tettagüen significa Abreojo. La ciudad de Tetuán fue fundada o por lo menos reedificada por tribus rifeñas a mediados del siglo XV y su nombre en lengua de esos kabileños, que no en árabe, significa Ojos de manantiales. He aquí la razón: la primera sílaba de ese nombre, o sea Tet, que los rifeños pronuncian Tity escriben (tit), significa Ojos, plural de ojo; y las dos restantes, o sean auen, que los árabes escriben (aiun) y losrifeños (auin), tanto en uno como en otro idioma quieren decir manantiales o fuentes. Además de esa razón, tengo otra para creer que la etimología ésta sea la verdadera, y es que hay en efecto en Tetuán gran número de fuentes, y uno de sus barrios se denomina EIAiun. Así pues (Titauin) escriben los rifeños, pero los árabes pronuncian (subrayado en el original) "Tettauen», y yo de este último modo lo transcribiría, porque el árabe tiene la fuerza de dos t.t. nuestras.

Ya sabe V., mi respetable amigo, que a mí no me molesta V. en lo más mínimo, antes al contrario, además de satisfacción, es para mí un honor insigne el que me utilice en cuanto quiera.

Lo que sí me apura y me cuesta trabajo es la necesidad en que me veo de pedir a $\mathrm{V}$. un grandísimo favor, no para mí, pero para un amigo mío a quien desearía con toda mi alma poder servir.

Se trata del señor Lúgaro, a quien yo tuve el gusto de presentarle en ésta. Es un pobre hombre, muy bueno, muy servicial, y con una carga de familia a mantener. A estas condiciones reúne la de ser muy versado en las cosas y quisicosas de este país, de conocer como nadie la política marroquí y de poseer una actividad increíble y muy valiosas relaciones en el Imperio. Era hasta hace dos meses corresponsal de «El Imparcial» y por una causa que desconozco, pero que estoy seguro, porque conozco al hombre, no puede afectar en nada a su buen nombre, fue sustituido, según tengo entendido, con carácter de interino (subrayado en el original), por otro que no es posible pueda elevarse a la altura que el crédito de ese periódico exije. Y el favor que yo deseo merecer de V., si es que ello es factible, consiste en que, si no hay inconveniente serio, $\mathrm{V}$. 
consiga del señor Gasset la restitución en su cargo de un hombre de cuyo españolismo y honradez respondo, no yo solamente, sino la Legación de España, la Comisión Militar Española y todos los elementos sanos por desgracia poco abundantes que aquí tenemos. Si V. puede conseguir esto hará V. una obra meritoria para la nación. Usted que tantas tiene ya hechas, para «El Imparcial» y para una familia honrada.

Ricardo Ruiz

(rúbrica)

Galdós a Ruíz Orsatti, 19 de diciembre de 1904.

« (...) Está dividida en cuatro partes. La primera es corta y pasa en Madrid; comprende los antecedentes y preliminares de la guerra. La segunda es la marcha del Ejército español de Ceuta al Río Martín, con las acciones del Serrallo, Castillejos, Monte Negro, parada en el valle de Capitanes, etc. Estas dospartes están hechas y son próximamente la mitad del libro. Y ahora entra la tercera parte que es la batalla de Tetuán, contada por un escritor marroquí. Este es un español renegado a quien he puesto el nombre de Sidi Mohammed Hach Ben Sur el Nariry. No sé si estará bien compuesto el nombre. La primera consulta de las muchas que tengo que hacer a Ud es ésta (...)".

Tánger, 15 de enero de 1905.

Señor don Benito Pérez Galdós.

Madrid.

Mi muy respetable y querido amigo: Recibí oportunamente la siempre grata de V. fecha 19 del pasado diciembre y no contesté enseguida por haber estado sumamente ocupado en un trabajo extraordinario primero y luego por haber tenido que guardar cama unos días a causa de un fuerte ataque de gripe. Hoy ya restablecido, desocupado y provisto de los datos necesarios me apresuro a escribirle, no sin rogar a V. disculpe mi forzado silencio.

Vamos por partes:

El nombre que adjudica $V$. a su héroe tiene un defecto de construcción. Haches título que se da a todo aquel musulmán que ha hecho la peregrinación a la Meca y va siempre precediendo al nombre propio del individuo que tiene derecho a usarlo. No es corriente su uso entre renegados, porque tal vez no exista ninguno que por haber efectuado el viaje a que aludo pueda tener ese derecho. Por otra parte, los individuos que abrazan el islamismo reciben generalmente el nombre de AbdAllah (Siervo de Dios) u otro de los atributos de Dios, v. g. Abd El Uahed (Siervo del Único), Abd El hatif (Siervo del Benigno), Abderrahman (Siervo del Clemente), etcétera. No llevan estos individuos apellido y sus hijos adaptan para este caso el nombre propio del padre, interpolando entre uno y otro el Ben (hijo), que es tanto como antiguamente entre nosotros el ezy entre los rusos el itch, con la diferencia que nosotros y los rusos lo usamos como afijo y los árabes como prefijo. Así pues su renegado podría llamarse correctamente AbdAllah,etc., o, si V. quiere, Sid AbdAllah. Si le quiere adornar con el Hach, entonces deberá V. decir Sid El HachAbdAllah y el apellido que $\mathrm{V}$. quiera siguiendo al nombre. 
Para que no haya lugar a confusión y por si se ve V. en el caso de ampliar la materia, no solamente le daré a continuación el equivalente de los meses de enero y febrero de 1860, sino la correspondencia de todos los meses del año 1276.

Meses Musulmanes del año 1276 corresponde

El 1. de Moharram » al 31 julio 1859

El 1. "Safar » al 30 agosto 1859

El 1. » Rabia el auel » al 28 septiembre 1859

El 1.․ " Rabia ettsani» al 28 octubre 1859

El 1.․ "Yumad el auel » al 26 noviembre 1859

El 1.․ "Yumadettsani» al 26 diciembre 1859

El 1.ㅇ »Reyeb » al 24 enero 1860

El 1. "Xaabán » al 23 febrero 1860

El 1.․ » Ramadán » al 23 marzo 1860

El 1. "Xaual » al 22 abril 1860

El 1. »DulKaada » al 21 mayo 1860

El 1. »DulHedcha » al 20 junio 1860

El 1. de enero de 1860 corresponde, pues, al 7 de Yumadettsanide 1276, y el 1. de febrero al 9 de Reyeb.

La invocación más generalizada en los libros musulmanes es la siguiente:

(Bi ismi Allah Errahman Errahim). (En nombre de Dios El Clemente, El Misericordioso).

También se emplea en unión de la anterior o aislada ésta:

(El HamdulilLah).

(Loor a Dios).

Con estas dos fórmulas empieza el Korán y todos los capítulos en que está dividido, excepción hecha del IX. Por esto, antiguos y modernos, todos los autores la usan en sus escritos como fórmula de introducción.

Por último, los moros dan a la puerta de Tetuán que nosotros denominamos de Fez el nombre de BabEnnuader.

BabEttsuts, a la del Cid.

BabErremmús,a la de los Reyes Católicos.

BabEloocla,a la de la Reina.

BabEssaida, a la de S. Fernando.

BabEdchiaf, a la de Alfonso VIII.

Bab El Mcabar, a la de la Victoria.

A la plaza de España llaman ellos El Feddán (El Daucal), a la del Teatro, El Gurna (por el matadero que allí existía. Hoy se hallan ahí el consulado español, la iglesia y la casa misión de franciscanos), a la de Pamplona, GarsaEsseguira, también la llaman Sok El Juts por el mercado de pescado o pescadería que hay actualmente en ella, a la de Sevilla, Garsa El Kibira (Huerta grande, por oposición a la anterior, cuya traducción es «huerta chica»).

El barrio hebreo es Ilamado por los moros El Mellaj,es decir lugar salado, con la misma acepción despectiva que entre nosotros tenía el lugar que era arrasado y salado en la edad media en guisa de exterminio y maldición. No recuerdo más que los nombres de dos barrios de la Judería: aluno le llaman El Prado y al otro Meca. 
Los principales lugares marcados en el plano son: «Campo de los juegos militares núm. 29 y Picadero núm. 28», que hoy se llaman El Gurna (matadero). "Hórreos de la Administración Militares" entre los moros la Rahbao mercado de cereales. "El jardín del Santo» es conocido entre los moros por «Dar El Conde», porque en ella, es decir en la casa que hay en él, habitó el famoso aventurero contemporáneo y aun creo que Ministro de Felipe V, Barón o Duque de Riperdá. Hoy y desde mucho antes de la guerra vive en ella la familia del venerado santón Sidi Ali Berraisun, tío del tan traído y llevado Raisuli secuestrador de Perdicaris. "El solar designado para la edificación de la casa consular», etc., es el Feddán de Lebady(Daucal de Lebady).

Calles: a la del Rey llaman los moros Kaiseria; a la de Chiclana, El Haddadin; a la de Cantabria, Trankats; a la de Barbastro, CaidHamed; a la del Darro, Muley AbdelkaderYilali; a la de África, Emtamar. En árabe, calle se dice «Zanka» o «Zankats». Generalmente, en todas las poblaciones de Marruecos, las calles llevan el nombre del más caracterizado de sus vecinos o del edificio más notable si lo hay en ella. V. g. a la calle donde está la Mezquita Principal llaman: ZankatsYama El Kibir; a aquella donde vive o tiene su tribunal koránico el Juez: Zankats El Kadi, etc.

No sé si he satisfecho sus deseos, pero no dude V. un momento en escribirme si algo más se le ocurre, pues ya sabe $V$. que con ello me proporciona un grandísimo placer. Me permito ofrecer a V. unas vistas de Tetuán por si pudieran ser de alguna utilidad para V.

Agradezco a V. muchísimo el interés que se sirvió tomarse en el asunto de que le hablaba en mi última referente a mi amigo el señor Lúgaro. Hoy ya no aceptaría la corresponsalía de «El Imparcial» aunque para ello fuera solicitado, porque ha sido nombrado recientemente corresponsal en Marruecos de la importante agencia "Central News». Puede estar satisfecho «El Imparcial» de su elección. Que compare, entre mil, la última noticia de su corresponsal actual informándole del notición inventado en el soco chico de Tánger por un guasón, referente a la proclamación en Marrakech de un Muley Hafid, canard que acojieron otros corresponsales tan listos como él para dar un nuevo motivo de alarma y un nuevo pretexto para hacer el juego a los extraños con perjuicio nuestro. En eso como en otras muchas cosas andamos por aquí a la zaga de los demás, y gracias al poco tacto en la elección de las personas lo que conseguimos es desacreditamos, perder cada día algún girón de nuestro maltratado prestigio y hacer el caldo gordo a los demás, inconscientemente, la mitad de las veces. No continuaré, porque en este diapasón pierdo los estribos ante tamaño desbarajuste.

Reciba muy afectuosos recuerdos de mi mujer $y$ ya sabe $V$. que dispone incondicionalmente desu devoto admirador y amigo

Ricardo Ruiz

(rúbrica)

P. D.

Abensur y otros amigos desean hacer unas ampliaciones del adjunto grupo y me encargan suplique a V. tenga la bondad de pedir a Victoriano que nos mande la placa (subrayado en el original).Le anticipa un millón de gracias en nombre de todos su más atto. amigo y s. s.

Ruiz

Galdós a Ruíz Orsatti, 11 de febrero de 1905 
“(...) Contesto a su amable carta del 15 de Enero; alegría por saber de Ud. y recibir sus gratas noticias de aquellas tierras; pena porque las noticias llegaban tarde. Al recibirlas, ya estaba yo terminando el tomo de AittaTettauen', obligado me ví a salir del paso con los datos incompletos, con recuerdos de lo que había oído a Ud., con diferentes libros contradictorios y sin duda equivocados en sus referencias. Sin duda, al leer este episodio encontrará Ud sin fin de errores y disparates. Me consuela la idea de que en otras obras hay, y gordos, sin exceptuar los libros de Historia, que traen las denominaciones árabes con infinidad de sílabas y letras que le vuelven a uno loco. En mi afán de buscar elementos de información, abrí los libros de R.; pero al asomarme a sus páginas me dio en la naríz el tufo de la inexactitud. Si será africanista el hombre que confunde a Badía con Murga.

Notará Ud. en Aita Tettáuen, como digo, muchos disparates. Los nombres de las puertas de Tetuán están todos equivocados. Sólo en los últimos capítulos están rectificados, porque felizmente llegaron a tiempo para el final los datos de su carta. Lo que no he podido rectificar, porque estaba ya impreso fue lo de El Hach, que apliqué al imaginario personaje El Nasiri. Pienso que el error no es grave porque se dice que la metamorfosis del español en marroquí fue conmpleta, y bien pudo el hombre hacer un viajecito a la Meca y engañar a toda la nación marroquí, como un personaje inglés, de cuyo nombre no me acuerdo, que hizo lo mismo no ha muchos años. Y en último caso, si cometí esa falta, perdóneme Allah, en gracia de que no fue mala mi intención.

El libro que me ha sido utilísimo, proporcionándome no pocas notas de carácter religioso, algunas con cierta inflexión cómica y pintoresca, ha sido el bendito Korán. Es un libro interesantísimo y de él he de sacar mucho partido en el tomo siguiente.

Y para concluir y no cansarla a Ud más, como verá Ud al leer el libro, que le enviaré un día de éstos, termino con la entrada de los españoles en Tetuán. Lo que falta para la completa historia (o lo que sea) de aquella guerra, lo llevaré al tomo siguiente en su primera parte. Describiré la estancia de los españoles en la ciudad. La acción de Uad-Ras. Las negociaciones para la paz y la paz misma. Para esto es menester que le marée a Ud de lo lindo y que cuando yo le comunique los datos que necesite para mi trabajo, se tome el idem de contestarme lo más pronto posible. Por de pronto (...)".

Tánger, 17 Febrero de 1905.

Señor Don Benito Pérez Galdós.

Madrid.

Mi respetable y muy querido amigo: El objeto primordial de la presente es el de presentar a Uste da mi distinguido amigo Señor de Kolemine, Secretario de la Embajada Rusa en ésa, muy hispanófilo y gran admirador de $\mathrm{V}$.

En su afición a las cosas de España ha entrado por mucho la lectura de sus obras de $\mathrm{V}$. a quien tiene vivísimos deseos de conocer personalmente, y yo me considero muy feliz con poder gracias a la benévola amistad con que $\mathrm{V}$. me honra servir de intermediario entre ambos. Reciba $\mathrm{V}$. por adelantado las más expresivas gracias por las atenciones que tenga para mi recomendado, $y$, con muy afectuosos recuerdos de mi mujer, Usted sabe que le quiere mucho y le admira su más atento servidor y amigo 
P. D.

Recibo su favorecida del 11, que contestaré esforzándome por complacer al maestro insigne.

Vale.

Tánger, 23 de Febrero de 1905.

Señor Don Benito Pérez Galdós.

Madrid.

Mi muy respetable y querido amigo:

No tuve paciencia para esperar el ejemplar que V. me anuncia y que yo le agradezco como regalo inapreciable, y adquirí otro de "Aita Tettauen». Acabo de leerlo de un tirón. Me parece imposible que haya quien pueda sustraerse al encanto e interrumpir la lectura. Es usted demasiado severo e injusto consigo mismo en su siempre grata y favorecida del 11 . Yo no lo juzgo a $\mathrm{V}$. porque ni tengo méritos ni condiciones, ni me deja para ello espacio la admiración, pero en cuanto se refiere al orden de mis modestos conocimientos, sí he de decirle que en ninguna, así como suena, en ninguna obra los he visto tratados tan de mano maestra. Es exactísimo e inimitable el lenguaje que Usted pone en boca de los judíos tetuaníes. Perfecta la literatura oriental del Nasiry. Los giros, las frases, las invocaciones de éste son de una asimilación acabada. Estoy seguro que no le escasearán sus elogios por este concepto nuestros distinguidos orientalistas. Los errores en nombres de calles o puertas son tan sin importancia que no hay que mencionarlos, aparte de que ya los corrije $\mathrm{V}$. al final.

Le diré a V. en contestación a su amable carta y como continuación de mis anteriores datos: El Guad El Jelúno existe más que en nuestros libros o cartas geográficas. Los indígenas en su conversación y en su literatura le llaman (en su desembocadura) Uad Martín. Lo de Jelú, a mi modo de ver, debe obedecer a que alguien, en tiempos de nuestra campaña o antes, preguntaría a algún moro el nombre del río. El indígena comprendería mal y contestaría refiriéndose al agua (no al río): Jelú, que quiere decir dulce, y de allí el error tan generalizado. No me lo explico de otro modo. Digo antes que le llaman Río Martín en su desembocadura, porque en su no largo curso recibe otras denominaciones: Emgaz el jayar(Vado de las piedras) se llama frente a Beni Madán, Emhannechfrente a Tetuán; un kilómetro más arriba recibe un afluente que se llama Quitan. Este riachuelo tiene la particularidad de que en su curso mueve un centenar de molinos harineros situados en un delicioso valle, y su origen es un pequeño lago que se halla en las montañas de Beni Hozmar, de aguas tan límpidas y cristalinas que por su color azul le llaman Zarca. Es lugar muy frondoso y poético. El Río Martín recibe también el nombre de Busfiha(nuestro Buceja) en el llano de Uadrás. Fíjese bien en este nombre; nosotros le llamamos Wad-Rás y hasta tenemos un regimiento con ese apelativo, pero debemos decir Uadrás, sin guión y sin doble $\mathrm{V}$, y la mejor prueba de que es así es que a los tribularios de aquella kábila les llaman Uadrasiy no drasicomo en el otro caso sucedería.

En la falda de la escarpada Sierra Bermeja se halla la aldea de Samsa, y, como creo que tendrá V. ocasión de hablar de ella, le diré a V. las particularidades más salientes. Muy cerca de 
ella existe un manantial de agua cristalina que brota abundante en todo tiempo por entre las peñas de Sierra Bermeja. Estas aguas tienen tal cantidad de cal (o lo que sea) que las cañas, caracoles, raíces y hojas que halla a su paso las petrifica en muy poco tiempo. Yo he cogido en este arroyuelo una hoja de yedra mitad aún fresca y la otra mitad, por estar dentro del agua, con una capa caliza como la cáscara de un huevo. En la falda de la sierra, a poco más de un kilómetro, hacia el Norte, de la aldea, hállase una gruta o mejor dicho una especie de túnel que perfora la montaña en un trecho de más de medio kilómetro. He penetrado con gran dificultad en él, y, aunque su forma me haga creer que aquello puede ser una galería abierta por la mano del hombre para explotar el subsuelo, no hallo vestigio de ello en ningún libro ni recuerdo queda por tradición entre sus vecinos.

En Hal-lila, aldea que se halla a unos cinco kilómetros al Sud Este de Tetuán entre Beni Hozmary Beni Madán, se crían unos melocotones célebres en todo Marruecos por su esquisito sabor y aroma. En Quitan se crían las famosas naranjas que salen de allí en cantidades de 10 a 15 millones todos los años con destino al extranjero. Las peras meskio moscateles son riquísimas y se crían en las huertas que rodean a Tetuán, así como las uvas moscateles de la campiña tetuaní y sobre todo las de Dar Murcia que son por lo menos iguales a las de Alicante o Málaga. El río Quitan da abundantes y ricas truchas que pescan, pero no comen los moros, por carecer de escamas (subrayado en el original). A raíz de la guerra, una compañía española explotó la cría del algodón con magníficos resultados en cuanto a la tierra y clima podía exigirse, no así en cuanto al apoyo que tales empresas necesitan por parte de las propias autoridades para su desarroyo (sic). En Beni Said, detrás de Beni Madán, he visto hace algunos años algunas plantas de dicho textil que crecían allí sin cultivo, reproduciéndose espontáneas. Creo que el valle de Tetuán sería muy apropósito parte para el cultivo de la caña de azúcar y parte para el del arroz.

Río Martín es el puerto natural de Tetuán, de la cual dista unos diez kilómetros. Del Rif afluyen cárabos, casi todos de la kabila de Beni Uriaguel, algunos de Badesy otros de Gomara, y a cambio de madera de alerce, cebada, sandías, miel riquísima, etc., se llevan de Tetuán telas de algodón, azúcar, hierro viejo (para fabricar azadas, arados y otros aperos de labranza), té, fusiles, etc.

Tetuán surte también de los productos de la industria europea, necesarios a los moros, a Xexuán, población que se halla a unos 60 kilómetros de Tetuán en la montaña de Beni Hassány el Jmás, al Surde Beni Hozmar. Aquella población es de las más fanáticas del Imperio, y el único europeo que pretende haber estado en ella es Foucauld vestido de judío. Estos (los judíos), en el Rif, el Atlas y otras regiones habitadas por Xlojsviven en servidumbre. Cada individuo o familia tiene su señor, y éste, a cambio de la gueziao capitación y otros servicios, es protegido por el señor contra las rapacidades de los correligionarios de éste. Entre los rifeños, por esta causa, los judíos son conocidos por el judío de fulano y no por sus nombres. Para el moro, el judío es Demmio individuo de un pueblo sometido. Para el judío, el moro y en general todos los no israelitas son Goi(creo que el plural es Goim).

Palabras del castellano anticuado o de árabe españolizado de uso corriente entre los judíos de Tetuán: La Meará (el cementerio). La joyerá: el escusado. Alasba: jovencita. Fidiondo: podrido. Niscaliá: mujer pública. Forno: horno. Tener el meollo huero: estar loco. Preto, Preta: Negro, Negra. Mazzal: suerte. Tienen un refrán que dice: "Daca un cuaxitodemazzaly tírame a las fondinasde la mar». Es decir: Dame un pedacito de suerte y tírame al fondo del mar. Maldiciones: Te venga el mal de la cabra: cuerno, sarna y barba. Te veas como el vapor: con agua en los lados y fuego en el corazón. Te veas como el café: tostado, molido, bebido y meado. Te venga un mal que te leve. Hijo de la baraniddahenconada (hijo concebido durante la menstruación de la madre).Bendiciones: Te haga el como esa cara pintada. No me alte tu jiar. Así te dé el Dió un 
azri(auna mujer encinta deseándole hijo varón). Varias frases: El Dió se apiade de nosotros. Me vaya capparápor ti. Dutor: médico. Tienen casi todos los tetuaníes un defecto de pronunciación que consiste en lo siguiente: a mí me llamaban Ricadro, dicen esta tadreen vez de tarde; esto es que la re que preceda a una de, la colocan ellos a continuación de ésta.

Varias industrias dan fama a Tetuán entre las demás poblaciones marroquíes. En primer

Otra de las industrias importantes de Tetuán, y ésta siempre floreciente, es la de los azulejos (zullej), de formas variadísimas y esmalte o vidriado muy persistente que usan los moros para revestir suelos y paredes.

También es de notar la de cortinas de seda de gran peso, mérito y valor que llaman ellos Zemzem, con las que cubren el lecho matrimonial y que se transmiten de padres a hijos duran temuchas generaciones. Duran siglos y cuestan de 500 a 1.000 pesetas los dos pares.

La de curtidos y su secuela de babucheros es la industria que hace ocupar a más gente en Tetuán. La primera produce los famosos tafiletes rojos y amarillos de pieles de carneros y suelas de no muy buena calidad adobadas con cueros de buey. Es sistema de curtir en estas tenerías es de los más primitivo. La tenería en árabe se llama Dar eddbagy el curtidor Debbag, plural Debbáguin.

Me han referido en Tetúan que, a raíz de la guerra de España, todos los moros principales enseñaron a sus hijos el oficio de zapatero, porque vieron, cuando evacuaron a Tetuán y emigraron a otras poblaciones de Marruecos, que aquellos que tenían algún oficio encontraban pan y patria en cualquier parte, mientras que los poderosos de ayer que nada sabían hacer tenían que recurrir a la caridad pública para comer, ya que sus riquezas habían sido abandonadas en la fuga o saqueadas por los montañeses.

Pretende una poesía árabe (cuyo texto y traducción le puedo enviar si quiere) que el año de la fundación de Tetuán se halla en el valor numérico de las letras que forman la palabra Tsefaha(manzana). Usted sabe que las letras árabes tienen su valor numérico como entre los romanos lo tenían las latinas. Según pues esta poesía, Tetuán se fundó el año 494 de la Hegira, que corresponde a1100-1101de nuestra cuenta. Se concluyó de edificar (siempre según dicha poesía) en 20 años y trabajaron en su construcción 240 hombres y 2 mujeres. Según otros el fundador de Tetuán o por lo menos el que convirtió el antiguo fuerte en una población fue Sidi Ali El Mendry, moro granadino cuya tumba se encuentra en Bab El Mecabar. El patrono de Tetuán es SidiSeidi. Una de las Mezquitas más veneradas es la edificada para panteón y en honor de Sidi Ali Ben Raisun, tío del famoso Raisuli de quien tanto se ha hablado en estos últimos tiempos.

Interrumpo aquí esta ya larga carta porque esperamos para hoy 3 de Marzo la tercera escuadra del Pacífico.

Me permití dar una carta de presentación para V. a mi amigo Sr. Kolemine, hijastro de mi jefe el Ministro de Rusia, que es un gran admirador de V. En la seguridad de que V. lo atenderá le anticipo un millón de gracias.

La madre de este Señor que ha leído todas sus obras traducidas, por no saber el español tiene un grandísimo deseo de poseer un autógrafo de Usted, y yo quisiera complacerla. Así pues me permito rogarle muy encarecidamente que me mande $\mathrm{V}$. lo que $\mathrm{V}$. crea oportuno, y si no se le ocurre otra cosa una tarjeta postal con algún pensamiento suyo. Se llama esta señora Madame $A$. de Bachérachty yo le vuelvo a suplicar a V. que la complazca, con lo cual me hará V. un señaladísimo favor. 
Deseo que no tema $\mathrm{V}$. molestarme en lo más mínimo siempre que a $\mathrm{V}$. se le ocurra algo. Si desea que amplíe alguno de los datos que van en la presente, indíquemelo; si necesita $\mathrm{V}$. algunos nuevos, mande. Siempre estoy a sus órdenes y en servirle tiene un gran placer y honor su más atto. amigo y s.s.

Ricardo Ruiz (rúbrica)

Dispénseme el papel que no puede ser más indecente. No tengo otro modo a mano y otra vez será mejor.

Tánger, 28 de Abril de 1905.

(Aquí de otra mano, probablemente de Galdós:) MadmeA. deBacheracht.

Señor Don Benito Pérez Galdós.

Mi muy respetable Señor y amigo: Hace algún tiempo contesté a V. algunas preguntas sobre este país, enviándole algunos datos que me prometía ampliarle a medida que $\mathrm{V}$. lo fuera solicitando. $\mathrm{O}$ aquéllos han sido suficientes o $\mathrm{V}$. me ha escrito pidiendo más y yo no he recibido su carta; lo que sentiría muchísimo porque habrá $V$. pensado que soy un perezoso, cuando para el servicio de $\mathrm{V}$. me transformo en el hombre más activo del mundo.

La señora de mi amistad de quien hablaba a V. en mi última, que tenía grandes deseos de poseer en su valiosísima colección de autógrafos uno de V., a quien admiraba, se ha marchado, no sin antes rogarme que solicite de nuevo de su esquisita amabilidad este singular favor. Ya sé yo que esto le carga y le molesta a V. mucho y hasta le roba un tiempo precioso, pero qué quiere V., el llegar a la celebridad mundial tiene también sus molestias, y ante el ruego insistente de una mujer hay que someterse.

He leído estos días que se va a publicar un periódico titulado "La República de las Letras» en el cual tiene $\mathrm{V}$. algo que ver. Si a la redacción interesan las cosas de este país, escuso decirle a V. que, siendo cosa de V., me ofrezco para lo que me crean útil. Podríamos publicar algunos estudios marroquíes ya desde el punto de vista político, social, comercial o religioso.

Usted verá.

Me entregó Cologan (hijo) la placa del grupo. Un millón de gracias. Espero el ejemplar de Aita Tettauen, dedicado, que V. tuvo la bondad de ofrecerme. Rinaldy, a quien una enfermedad de la vista le impide escribir, me encarga le diga a $\mathrm{V}$. lo muchísimo que le agradece el retrato que de él hace.

Reciba afectuosos recuerdos de mi mujer y $\mathrm{V}$. sabe que dispone incondicionalmente de su más atto. amigo y s. s.

Ricardo Ruiz

(rúbrica) 
«Marruecos» Tánger, 14 de Agosto de 1908.

Revista Española y de Intereses Generales (Marruecos)

(Se publica el 1. y el 16 de cada mes)

Director: Ricardo Ruiz.

Señor Don Benito Pérez Galdós.

Santander.

Muy respetable e ilustre amigo: ¿Se acuerda V. todavía de mí? Yo continúo siendo cada vez más admirador de $\mathrm{V}$. y con todo el respeto que $\mathrm{V}$. me merece me permito molestarle hoy para solicitar de $\mathrm{V}$. un singular favor.

El día 1.o de Septiembre empezaré a publicar una revista quincenal cuyo título encabeza esta carta. ¿Querría V. honrarla enviándome para el primer número una cuartilla con recuerdos de su inolvidable viaje a Tánger?

Rogando a V. me perdone el atrevimiento y dándole un millón de gracias anticipadas, se repite de V. el más atento amigo y devoto admirador, q. I. b. I. m.

Ricardo Ruiz

(rúbrica)

Tánger, 25 de Octubre de 1910.

Señor Don Benito Pérez Galdós.

Mi muy respetable amigo: A mi vuelta de una excursión por el Rif, donde he estado documentándome para un trabajo que hace ya tiempo tengo entre manos, titulado "Desde el Muluya al Sebú», dos de cuyos capítulos han sido publicados por la Real Sociedad Geográfica, me he encontrado la cariñosa carta del buen amigo Valeriano, a quien escribo hoy mismo, con el temor de que sea demasiado tarde para su objeto.

Ya sabrá V., porque el proyecto se halla consignado en el presupuesto del Ministerio de Estado leído últimamente en el Congreso, que aquel Departamento ha decidido crear un "Centro de Estudios Marroquíes», cuya falta se hacía sentir para acabar con tanta fantasía morisca como ha propagado la nutrida literatura hispano-marroquí. Gracias a este centro podrá al fin saberse en España la verdad sobre este país interesantísimo y tan distinto de todo lo conocido. Pero esto a condición de que los que lo formen no sean otros tantos cultivadores de la farsa corriente.

Ya sabe V. lo que yo, por haber nacido aquí, por conocer el árabe como mi propia lengua y por mis aficiones al estudio del Marruecos verdadero, conozco de este país.

Ello me ha inducido, sin huera vanidad, a creer que estoy en condiciones, que ningún otro español puede reunir, para dirigir ese centro, y para conseguir este propósito es para lo que hoy me decido a molestarle, rogándole me perdone la molestia que le ocasiono.

Usted puede hacer mucho por mí en esta ocasión, mi venerado y admirado amigo, bien recomendándome, con la eficacia que $V$. puede hacerlo, a sus amigos que directa o indirectamente hayan de influir en la designación, o bien publicando, en recuerdo de "Aita Tettauen», algún suelto en un periódico de su predilección, hablando de mi modesta persona y de mis conocimientos positivos de Marruecos y sus habitantes. 
Vuelvo a suplicarle me dispense la molesta pretensión con que he interrumpido un tan largo silencio, pero el convencimiento de su mucha indulgencia y de que su intervención puede ser decisiva para la realización de mi ideal me han decidido a ello.

Algo ha variado este país desde su viaje de V. a Tánger. Aunque lentamente, la tan traída y llevada conferencia de Algeciras va dando sus frutos, sobre todo en la periferia. El interior ve aún con indiferencia no exenta de algún recelo el movimiento evolutivo. Por ahora la tranquilidad es completa. Puede viajarse por estos malos caminos de herradura con menos comodidad, seguramente, pero con harto más seguridad que por las asfaltadas avenidas de la gran urbe parisiense. El peligro apache es mucho más grande que el ofrecido por estos desgraciados e ignorantes marroquíes. Por la parte de Melilla el país está sometido, pero no tan dominado y sojuzgado como había derecho a exigir teniendo en cuenta que para ese resultado fueron empleados unos sesenta mil hombres. Ello es la consecuencia lógica de la falta de preparación, del desconocimiento inconcebible que en España se tiene de Marruecos. Con preparación y conocimiento sobraban las dos terceras partes de aquel extraordinario contingente de tropas para obtener un resultado mucho más positivo. Pero tal es nuestro sistema: dejarlo todo al azar y resolver después por la fuerza lo que pudo evitarse con más conocimiento y previsión.

Nada más por hoy que expresarle de nuevo mi agradecimiento por cuanto se digne hacer a favor mío y reiterarle mi admiración inquebrantable con las seguridades de mi más distinguida consideración.

L. e. I. m. su afmo. amigo

Ricardo Ruiz

Villa Calpe

Tánger 